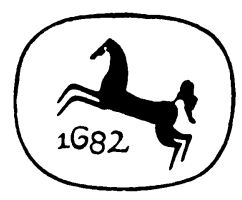

MATERIALIEN

FUR DIE STAATSBURGERLICHE FORTBILDUNG 


\title{
FRIEDRICH OETINGER
}

\section{FREIHEIT \\ DIE ICH MEINE}

\author{
Materialien für die Erziehung \\ zur politischen Freiheit
}

J. B. METZLERSCHE VERLAGSBUCHHANDLUNG STUTTGART 
ISBN 978-3-476-99098-3

ISBN 978-3-476-99097-6 (eBook)

DOI 10.1007/978-3-476-99097-6

(C) 1955 Springer-Verlag GmbH Deutschland

Ursprunglich erschienen bei J. B. Metzlersche Verlagsbuchhandlung und Carl Ernst Poeschel Verlag GmbH 1955 
Vorbemerkung

»Der Mensch ist frei geschaffen, ist frei, und würd er in Ketten geboren!«

"Der Mensch ist nicht geschaffen, frei zu sein"

Von der Freiheit eines Christenmenschen

Alles tun dürfen, was anderen nicht schadet?

Freiheit vom Staat - Freiheit zum Staat

Deutsche Freiheitsträume

Freiheit in der Vergangenheit und Freiheit in der Zukunft

Freiheit und Zwang $\quad 29$

Beispiele heutiger Unfreiheit

Die institutionellen Sicherungen der Freiheit im Rechtsstaat

Herrschaft der Mehrheit über die Minderheit

Keine Freiheit ohne unabhängige Rechtsprechung 40

Freiheit von Angst

Freiheit und Gleichheit

Eine verborgene Weise der Unfreiheit 47

Sicherung der vitalen Interessen $\quad 50$

Man muß etwas tun für die Freiheit! 53

Weniger Herrschaft, mehr Partnerschaft! 57

Erziehung zur Selbstverwaltung $\quad 61$

Das Ende der Freiheit $\quad 65$

Freiheit - Ordnung - Führung 69

$\begin{array}{ll}\text { Schlußbemerkung } & 71\end{array}$

$\begin{array}{ll}\text { Literaturhinweise } & 72\end{array}$ 